\title{
Social activity and participation as determinants of anxiety and depression among elderly in primary care
}

\author{
Ilias Grammatikopoulos ${ }^{1 *}$, Constantine Koutentakis ${ }^{2}$ \\ From $1^{\text {st }}$ International Congress on Neurobiology and Clinical Psychopharmacology and European \\ Psychiatric Association Conference on Treatment Guidance \\ Thessaloniki, Greece. 19-22 November 2009
}

\section{Background}

Aim of this study was to investigate anxiety disorders and depression among members of one Open Care Centre for the Elderly (KAPI) in Crete-Greece, in correlation with their activity and participation levels.

\section{Materials and methods}

A cross-sectional study was designed and 132 aged $(\geq 65)$ participated. All participants were members of the KAPI from a rural district in Crete, Greece. Data were collected with face-to-face interviews. Social activity and levels of participation in KAPI were examined. The Short Anxiety Screening Test (SAST) and the Geriatric Depression Scale (GDS-15) was used to assess anxiety disorders and depression respectively. Univariate and multivariate regression models used to determine the factors which correlate with these disorders.

\section{Results}

132 aged (mean age 75.7 years) participated. $18,2 \%$ had minor depression (GDS $\geq 7$ ) and $8,3 \%$ moderate to severe depression (GDS $\geq 11$ ), while $17,4 \%$ ( $6,8 \%$ men vs $26,4 \%$ women) had an anxiety disorder according to SAST ( $\geq 24)$. According to univariate regression models, increasing age, female gender and the absence or minor participation in KAPI were associated with higher risk of depression; low levels of participation in KAPI and female gender were associated with higher risk of anxiety.

\section{Conclusions}

Our findings document the association of higher prevalence of anxiety and depression in elderly with limited social activity in primary care centres, and especially affect more women and aged in widowhood. These determinants of isolation should be factors of mental health prevention management in primary care.

\section{Author details}

'B' University Clinic, Psychiatric Hospital of Thessaloniki, Thessaloniki, Greece. ${ }^{2}$ Department of Social Medicine, Faculty of Medicine, University of Crete, Heraclion, Crete, Greece.

Published: 22 April 2010

\section{References}

1. Fountoulakis K, Tsolaki M, lacovedes A, Yesavage J, O'Hara R, Kazis A, lerodiakonou C: The validation of the short form of the Geriatric Depression Scale (GDS) in Greece. Aging (Milano) 1999, 11:367-372.

2. Sinoff G, Ore L, Zlotogorsky D, Tamir A: Short Anxiety Screening Test-a brief instrument for detecting anxiety in the elderly. Int J Geriatr Psychiatry 1999, 14(12):1062-1071.

3. Wittchen HU, Kessler RC, Beesdo K, Krause P, Höfler M, Hoyer J: Generalized anxiety and depression in primary care: prevalence, recognition, and management. J Clin Psychiatry 2002, 63(8):24-34.

4. Papadopoulos FC, Petridou E, Argyropoulou S, Kontaxakis V, Dessypris N, Anastasiou A, Katsiardani KP, Trichopoulos D, Lyketsos C: Prevalence and correlates of depression in late life: a population based study from a rural Greek town. Int I Geriatr Psychiatry 2005, 20:350-357.

doi:10.1186/1744-859X-9-S1-S137

Cite this article as: Grammatikopoulos and Koutentakis: Social activity and participation as determinants of anxiety and depression among elderly in primary care. Annals of General Psychiatry 2010 9(Suppl 1):S137. 